\title{
The Communication Effects of Audience Situation and Message Framing on Smoking Cessation
}

\author{
Dong-Jenn Yang \\ Dept. of Business Administration, I-Shou Iniversity, Taimintll

\begin{abstract}
This study examined the communication effects of smoking cessation by using message framing (positive messages/negative messages) and audience situation (smoker/nonsmoker and high/low self-efficacy). The study used 207 valid homogeneous subjects and a between-subject experiment method was employed for analyses. The results showed that the communication effects were influenced by the interactive effects of message framing and audience situation, and for smokers, positive messages have a more significant effect than negative ones. In addition, positive messages with low self-efficacy have a better effect. The study concludes that different message framing have a variety of communication effects on audiences within different self-efficacy levels and audience situations.
\end{abstract} \\ Keywords: Message framing, audience situation, communication \\ effect, smoking cessation, social marketing \\ JEL: M31, K32, I18
}

Cigarette smoking is the major preventive cause of death worldwide (Oster, Colditz, and Kelly, 1984), and various social marketing efforts have been used in an attempt to address this problem. Although fear (negative emotion) appeals are commonly used for anti smoking campaigns (Rossiter and Thornton, 2004; Rutsohn and Sikula, 2007; Dickinson and Holmes, 2008; Brennan and Binney, 2010), these still remain controversial, in particular with regard to ethical concerns and their real effectiveness (Elliott, 2005; Hastings, Stead and Webb, 2004). However, recent research has found that hope (positive) advertising appeals should be respected because of the following reasons: Firstly, people with higher hopes are more likely to attain their goals by achieving sub-goals which

Manuscript received September 5, 2013; revised November 20, 2013; accepted December 2, 2013.

Corresponding author Email: alimama@isu.edu.tw are driven by lofty goals (Snyder, 1994; Snyder et al., 1991). Secondly, research has shown that high hope individuals can cope better with obstacles because they are prone to having multiple routes, allowing them to better handle or avoid the stress and negative emotions often associated with setbacks (Snyder, 2002).

Laskey, Fox and Crask (1995) put forward the view that commercial effectiveness has a relationship with message strategy. Moorman and van den Putte (2008) report a substantial amount of literature exploring the different effects that positive and negative messages have on individual health topic decision-making, such as the detection of breast cancer at an early stage (Banks et al., 1995; Meyerowitz and Chaiken, 1987; Rothman et al., 1993) and smoking cessation (Wilson et al., 1990; Wong and McMurray, 2002). Chang (2007) argues that positively framed messages are more effective 
when people are in a negative mood, whereas, messages framed negatively are effective when people enjoy a positive mood. In addition, many studies have shown that personality traits have an impact on communication effects (Dutta and Vanacker, 2000; Cheng and Wu, 2010). Reardon and Miller (2008) found that the frequency of advertising messages has no significant effect but positive messages have a better effect than negative messages on teenagers regarding attitudes toward advertising and the intention to stop smoking. This study examined the communication effects of message framing with personality traits and audience situations and puts forward the best way to get a good response to smoking cessation communications.

\section{LITERATURE REVIEW}

This study examines the attitudes toward adverting and the acceptance of ideas to ascertain the communication effects under different message framing scenarios and different audience situations.

\section{Communication Effect}

Shimp (1981) believes that attitude is a very important factor in advertising communication. Similarly, Lutz (1985) considered attitudes toward advertising as a tendency to either like or dislike the stimulation of the given advert in a specific condition. Therefore, attitudes toward advertising come from learning and form cognition. This then influences the feelings of a subject and even their actions.

Fishbein and Ajzen (1975) used the communication and persuasion model, proposed by Hovland and Janis (1959), to explain the importance of message communication. This indicates that if people want to change an audience' $s$ attitude, the precondition is for the message to be noticed, understood and accepted. Therefore, the acceptance of smoking cessation ideas can represent the suitability of the communication effect.

\section{Message Framing and Audience Situations}

Message framing means the message is delivered in either a positive or a negative way. A positively framed message emphasizes the benefits if the audience follows the message. Whereas, negatively framed message emphasizes the losses if the audience doesn' $t$ take a certain action (Meyerowitz and Chaiken, 1987; Maheswaran and Meyers-Levy, 1990). Shimp (1981) come up with the idea that different products should use different advertising strategies, depending on the basic information that the products deliver to consumers.

Rothman and Salovey (1997) proposed that positive messages are better for helping people to maintain their health while negative messages are used to persuade people to be aware of potential risks or illness and to convince them not to do something. People who know a little about the subject accept a positively framed message easily because they don' t want to affect their mood. Literature reflects that scholars always use the prospect theory to explain fear. Therefore, appeals can be used to show the consequences that an audience would want to avoid and that to allow them to feel threatened, fear and pressure before they start to take positive action to avoid the unwanted consequences (Tversky and Kahneman, 1981; LaTour and Rotfeld, 1997). 
International Journal of Management, Economics and Social Sciences

Negative messages have a better effect when they are used for a preventive health issue. Therefore, activities, such as anti-smoking behaviour, female breast self-examination, fastening seat belts while driving, and skin cancer prevention inspection, are more effective if they are presented as a positive message (Ruiter et al., 2003). Smokers, who carry a high risk of becoming ill, are better persuaded to quit using negative methods. However, according to the broken windows theory (Wilson and Kelling, 1982), smokers may continue smoking or stop their quitting smoking. Witte (1992) also proposes the extended parallel process model (EPPM). This model points out that if an individual perceives a significant threat and thinks that he has the ability to avert the threat, " danger control" , he will be more likely to accept the recommended action. In contrast, high levels of threat and low perceived efficacy yield " fear control", which consists of efforts to reduce the unpleasant experience of fear by avoiding, ignoring, or denying the means of the message. Therefore, positively framed messages will reinforce hope and allow smoking audiences to manage their "danger control". Meanwhile, negatively framed messages strengthen fear and let them experience "fear control". Based on the above discussion, the following hypotheses are proposed:

$\mathrm{H}_{1}$ : For non-smokers, a negatively-framed message results in better communication (attitude/acceptance of ideas) effects than a positivelyframed message about anti-smoking.

$\mathrm{H}_{2}$ : For smokers, a positively-framed message results in better communication (attitude/acceptance of ideas) effects than a negativelyframed message about stopping smoking.

$\mathrm{H}_{3}$ : Attitude and the acceptance of ideas are influenced by the interactive effect of message framing and audience situation (smoker/non-smoker).

\section{Self-Efficacy}

Lin (2005) defines personality traits as people' s psychological characteristics. Based on these psychological characteristics, people have a continuous and steady response to their environment. Therefore, personality traits include psychological and environmental factors.

Self-efficacy, or a belief in one's personal capabilities, is the level of confidence to succeed in something and determines whether someone can conquer difficulties (Bandura, 1997; Holloway and Watson, 2002). Bandura (1997) proposes that people with high self-efficacy are more likely to have strong motivations and meet challenges firmly. Rosenstock, one of the founders of the health belief model, proposes adding selfefficacy to the model (Rosenstock, Strecher and Marshell, 1988). Hence, self-efficacy is an important mental mechanism to moderate or enhance fear control and hope achievement.

The results of many studies mention that the theory of planned behavior, with the addition of self-efficacy, has more predictive power than attitude on behavior intention and behavior (Ajzen, 1991; Godin and Kok, 1996). In addition, the EPPM points out that if an individual has more self-efficacy, he has great ability to oppose the threat (Witte, 1992). Thus, when an individual 
thinks he has the skills or confidence to prevent the threat, he may be motivated to rebel against a threatening message.

In this research, self-efficacy to quit smoking is selected as the criterion, which is supported as an important indicator of smoking cessation behaviour (Badr and Moody, 2005; De Vries and Backbier, 1994). This selection is made to propose the relationship between appeal design (i.e., fear and hope appeals) and the selfefficacy to quit smoking. Hence the following hypothesis is proposed:

$\mathrm{H}_{4}$ : The attitude/acceptance of ideas is influenced by the interactive effects of message framing and self-efficacy.

\section{METHODOLOGY}

\section{Research Framework}

The research was designed to examine the effects of smoking cessation communications using the three variables i.e. message framing (positive messages/ negative messages), audience situation (smoker/nonsmoker) and high/low self-efficacy. The communication effect includes the attitudes toward advertising and the acceptance of ideas. The research framework is illustrated in Figure1.

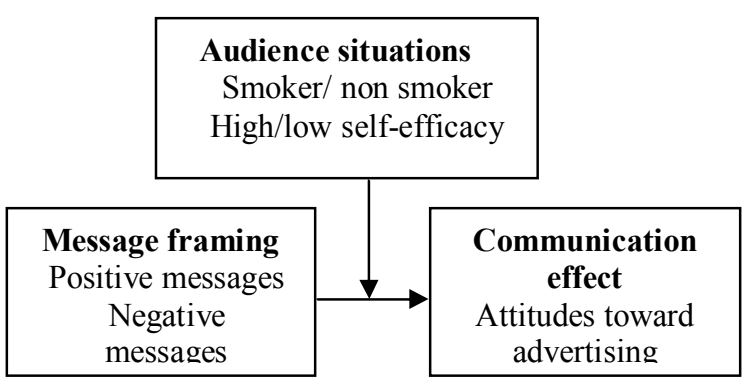

Figure 1. Research framework

\section{Advertising Frame Design}

The design of the advertisement content of the study was purely text manipulation and excluded pictures. The design of the advertisement content was based on the information regarding quitting smoking to improve health, provided by Huang (1998). The advertisement content showed how smoking damages health and how cessation will improve the body, including three versions of the advertisement content, as per Table 1 (see Appendix-l). In order to explore whether the subjects have impressive positive/negative feelings about the official questionnaire, 60 college students selected the most emotional advertisement content for smoking cessation and counted frequency. It was found that the " $\mathrm{C}$ advertisement content" had the most perception of positive/negative messages. Therefore, the framing of the "C advertisement content" was selected as the official advertisement content of this study.

\section{Experimental Designs and Samples}

The experiment was a two message frame between subject design. The self-efficacy and communication effects were measured by a standard questionnaire. A homogenous sample of 220 undergraduate students from the I-Show University in Taiwan participated in this experiment. 60 smokers were adopted as purposive samples, and the other 160 were convenient samples. There were 207 valid replies (response rate $94.09 \%$ ) to the questionnaire. Participants were given either a positive or a negative advert at random. Firstly, the subjects were required to answer the self-efficacy questions, and to then read the advert and reply to questions about the communication effect. 
International Journal of Management, Economics and Social Sciences

\section{Reliability and Validity}

With regard to the attitudes toward advertising and the behavioral intentions of the subjects, various scales were used to measure the communication effect. The attitudes toward advertising were measured using three 7-point semantic differential items in response to the adverts were separated into two different kinds (positive/negative), and each questionnaire consisted of two questions. The positive messages and negative messages had significant differences, meaning that the message framing manipulations were successful. The results are shown in Table 2.

\begin{tabular}{ccccccc}
\hline $\begin{array}{c}\text { Ad } \\
\text { content }\end{array}$ & $\begin{array}{c}\text { Message } \\
\text { framing }\end{array}$ & $\mathbf{n}$ & $\mathbf{M}$ & S.D & $\boldsymbol{t}$ & $\boldsymbol{p}$ \\
\hline $\begin{array}{c}\text { Positive } \\
\text { messages }\end{array}$ & Positive & 96 & 5.53 & 0.53 & & \\
& Negative & 96 & 3.30 & 1.01 & 34.58 & $<0.001$ \\
\multirow{2}{*}{$\begin{array}{c}\text { Negative } \\
\text { messages }\end{array}$} & Positive & 111 & 2.58 & 0.85 & & \\
& Negative & 111 & 5.62 & 0.68 & -45.59 & $<0.001$ \\
\hline
\end{tabular}

Table 2. The manipulation check of message frames

question, "What are your thoughts about the advertising?" with scales stating 1. favorable/ unfavorable 2. impressive/ unimpressive 3. like/ dislike (Yi, 1990; Coulter and Punj, 1999; Yang and $\mathrm{Ma}, 2011)$. The Cronbach's alpha result was 0.68. The acceptance of ideas was measured by three 7-point Likert items in response to the question, 1. How much do you intend to adopt smoking cessation? 2. Would you try to quitting smoking/ anti-smoking? 3. Would you want to share quitting smoking/anti-smoking messages with friends? (MacKenzie and Lutz, 1989). The Cronbach's alpha coefficient for behavior intention was 0.69 and for self-efficacy Cronbach's alpha was 0.95, using 10 items measurement scale by Zhang and Schwarzer (1995). All the constructs of the Cronbach's alpha were higher than 0.68 , indicating that the questionnaires had good reliability.

This study' $s$ validity analysis focused on the manipulation check of the advertisement. The

\section{RESULTS}

The Communication Effect of the Message Framing with Audience Situation

Through independent sample t-test, the results showed that the message framing had no significant effect on the attitudes toward advertising $(\mathrm{m}=6.18 / 6.15 ; \mathrm{sd}=0.53 / 0.39 ; t=0.25$; $p>0.05)$ or the acceptance of ideas $(\mathrm{m}=5.78 / 5.86 ; \mathrm{sd}=0.29 / 0.66, t=-.75, p>0.05)$ by the non-smoking participants. However, the message framing had a significant effect on the attitudes toward advertising $(m=6.07 / 5.48$; $s d=0.71 / 1.12, \quad t=3.44, p<0.001)$ and the acceptance of ideas $(m=5.77 / 5.60$; $s d=0.40 / 0.66, t=3.80, p<0.001)$ by smoking participants. Additionally, the positive messages showed better communication effects than the negative ones for smokers. Therefore, $\mathrm{H}_{2}$ was supported, whereas $\mathrm{H}_{1}$ was rejected.

Through a two-way ANOVA analysis, it was shown how the message framing, interacting with 
audience situation (non-smoker/ smoker), better communication effects (attitudes toward affected the attitudes toward advertising and the advertising and the acceptance of ideas) than acceptance of ideas. In Table 3 (see Appendix- the negatively-framed messages for smokers. II), the results show that message framing has an Therefore, $\mathrm{H}_{3}$ was supported.

interaction with audience situation regarding the The Communication Effect of Message Framing attitudes toward advertising and the acceptance of with Self-Efficacy

ideas.

Therefore, attitude and the acceptance of ideas are influenced by the interactive effect of
A two-way ANOVA analysis was undertaken to ascertain whether message framing interacting with self-efficacy (high/ low) affected the attitude

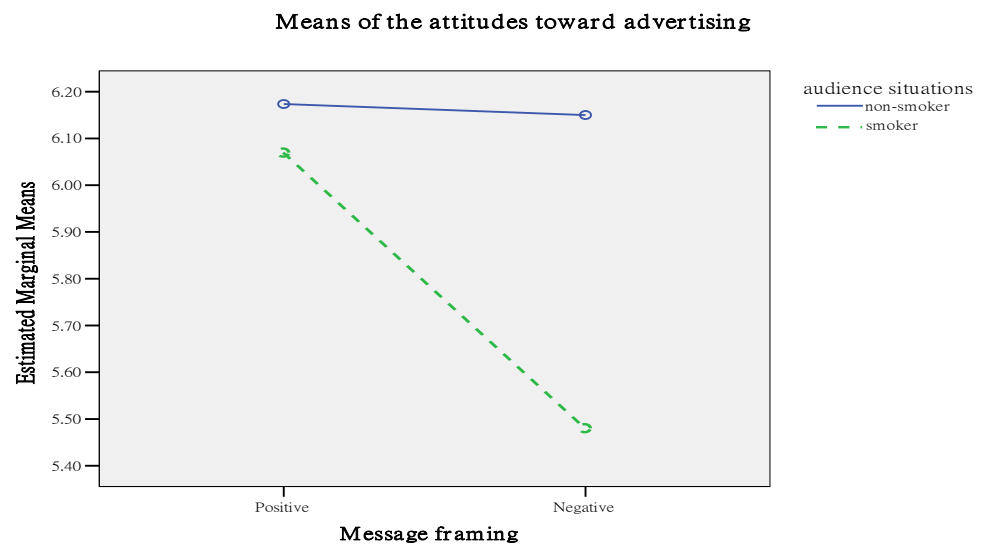

Figure 2. The attitudes toward advertising of the message framing with non-smoker/smoker

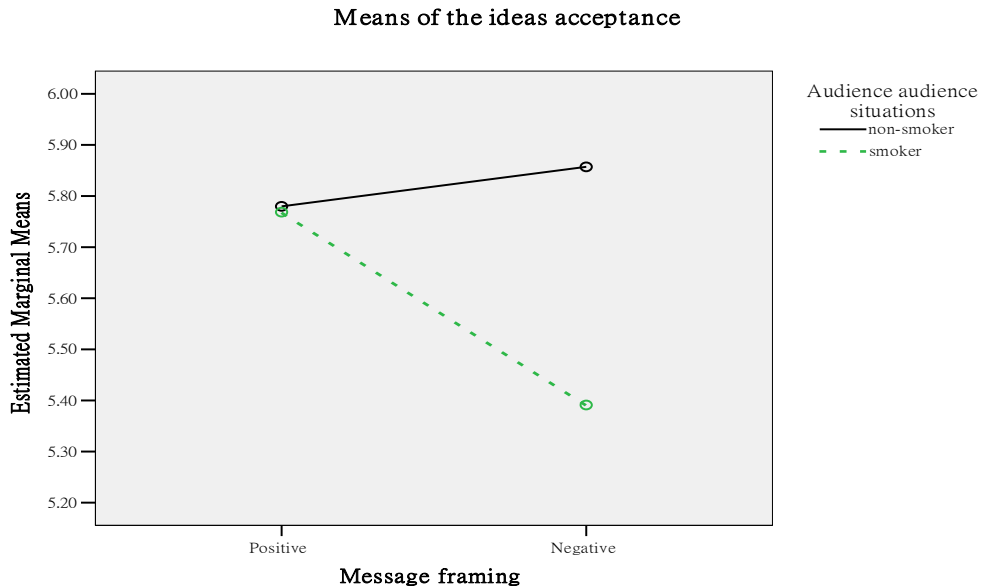

Figure 3. The acceptance of ideas of the message framing with nonsmoker/smoker

message framing and audience situation toward advertising and the acceptance of ideas. (smoker/non-smoker). In figures 2 and 3 above, In Table 4 (see appendix-II), the results showed noticeably, the positive framing messages had that message framing had an interaction with 
self-efficacy regarding the acceptance of ideas, but had no significant effect on the attitude toward advertising. Therefore, the acceptance of ideas was influenced by the interactive effect of message framing and high/low self-efficacy. Hence, $\mathrm{H}_{4}$ was partly supported. The positively framed messages had better idea acceptance than negatively framed messages for subjects with low efficacy. In contrast, the negatively framed messages had better idea acceptance than positively framed messages for subjects with high efficacy (Figure-4). an individual can perceive threat messages significantly and will think carefully, so they have a bigger reaction to the different message framing. These explanations are similar to the filter model of selective attention proposed by Broadbent (1958) who emphasized that people have cognitive processes to focus on relevant targets on input, thoughts or actions while neglecting irrelevant sources of input. If messages are exploratory, the audience may not pay attention or generate a perception. An audience will only have perceptual sensitization

Means of the ideas acceptance

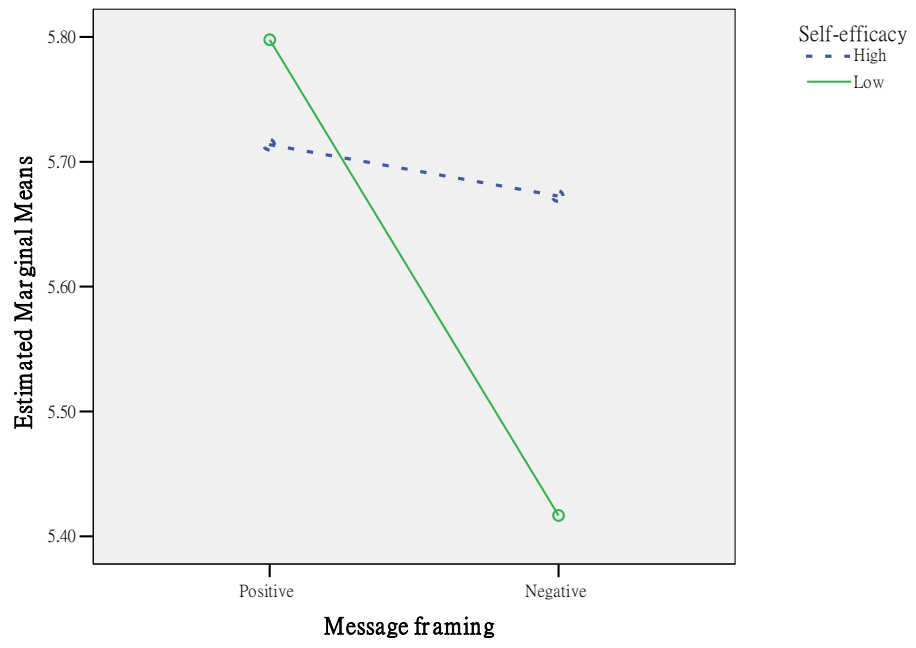

Figure 4. The acceptance of ideas of the message framing with Self-efficacy

\section{DISCUSSION}

For non-smokers, the effect of different message framing has no communication effects on antismoking. As non-smokers do not perceive or suffer from any of the dangerous situations featured in the advertising, different message framing does not significantly stimulate different communication effects. In contrast, for smokers, and pay attention to messages that relate to them (Hsu, 2003), and a higher correlation can affect the audience' $s$ behavior and attitudes. Therefore, smoking messages and the message framing make the smokers react differently.

The acceptance of ideas was influenced by the interactive effect of message framing and self-efficacy but the attitude toward advertising 
was not. The acceptance of ideas needs individual intention or active thinking of smoking cessation. In addition, it has a high-level relationship with self-efficacy. However, the attitude toward advertising is as a result of the evaluation of advertising messages. Snyder (2002) has shown that high hope individuals are better able to cope with obstacles because they are prone to have multiple routes, allowing them to better handle or avoid the stress and negative emotions often associated with setbacks. This is especially important for low self-efficacy audiences. However, allowing individuals to perceive threats (or benefits) and dropping active or agency thinking situations are very important in social communication marketing.

\section{CONCLUSION}

The experiments show that different message framing for different audience situations has a better communication effect. Positive messages have a better effect on attitudes toward advertising and the acceptance of ideas for smokers. For smokers, no matter their selfefficacy, a negatively-framed message has a lower communication effect than a positively framed one. The smoking cessation advertisements with warnings that use negative ideas or fear appeal, work on the same principle. A smoker, who may negatively believe that his or her health has already been destroyed, may then have no intention to quit smoking. In fact, for smokers, using negatively framed messages will enhance their fear. Is this then an ethical problem of social marketing?
Message framing with self-efficacy has a significant difference on the acceptance of ideas, which means that different message framing for different individual self-efficacy has a better communication effect. Positive message appeals with low self-efficacy have a better effect on attitudes toward advertising. According to the health belief model (Rosenstock, et al., 1988), perhaps there exist perceived barriers against taking action. Taking a person who is going to quit smoking as an example; he may believe that stopping smoking is painful and uncomfortable. Therefore; all these negative factors are barriers against taking action. The health belief model believes that the more barriers there are the less possibility there is of taking action. Therefore, the strategy of message framing and the segmentation of audience situations are useful for smoking cessation in social marketing.

The hope theory (Snyder, 2002), informs that hope is the perceived capability to derive pathways to desired goals, and of agency thinking to use those pathways. Therefore, smokers who have little confidence in their ability to quit smoking and who have low self-efficacy, will gain hope, reduce the barriers against taking action and increase their willpower when they are exposed to positive ideas. This indicates an apparent effect from positive ideas on people with low self-efficacy. These results satisfy the extended parallel process model (EPPM).

A few of the hypotheses were not significant, meaning that other influential variables, such as perceived threats/benefits and action thinking, may exist that leads to the cessation of smoking action. 
International Journal of Management, Economics and Social Sciences

\section{IMPLICATIONS}

The results show that market segment theory is useful for smoking cessation marketing. For smoking target audiences, using positive messages has a better communication effect than negative messages, and to avoid any fear, messages may raise social marketing ethical considerations; specifically, that the use of threat-based advertisements to manipulate smokers is unethical. For non-smokers, using negative messages has a better deterrent and avoidance effect. In addition, the self-efficacy of audiences is also an important factor. Giving the smokers with low self-efficacy positive or hope messages will enhance their self-efficacy and achieve better communication effects.

\section{LIMITATIONS AND FUTURE DIRECTION}

Results from this study show an interesting communication effect between the message framing and audience situations. However, several theoretical issues remain unresolved. First, the fear or the hope of encoding an audience' $s$ mind that guides their processing of information between the message framing and audience situation is not clear. Second, the process of communication effect in an individual' $s$ mind has not been investigated by this research. Third, the effect of smoking cessation advertising on attitude and ideas accepted, but not behavior, was the focus. Finally, for internal validation, the subjects of this study used college students. Therefore, the conclusions generated to others should be made with caution. All these research issues can be addressed for future research, which would decrease the knowledge gaps regarding the communication effects between message framing and audience situations.

\section{REFERENCES}

Ajzen, I. (1991). The theory of planned behavior. Organizational Behavior and Human Decision Processes, 50(2): 179-211.

Badr, H. E. \& Moody, P. M. (2005). Self-efficacy: A predictor for smoking cessation contemplators in Kuwaiti adults. International Journal of Behavioral Medicine, 12, 273-277.

Bandura, A. (1997). Self-efficacy: the exercise of control. New York: Freeman.

Banks, S. M., Salovey, P., Greener, S., Rothman, A. J., Moyer, A. \& Beauvais, J. (1995). The effects of message framing on mammography utilization. Health Psychology, 14, 178-184.

Brennan, L. \& Binney, W. (2010). Fear, Guilt, and Shame appeals in Social Marketing. Journal of Business Research, 63(2): 140-146.

Broadbent, D. (1958). Perception and communication. London: Pergamon Press.

Chang, C. T. (2007). Interactive effects of message framing, product perceived risk, and mood-The case of travel healthcare product advertising. Journal of Advertising Research, 47(1): 51-65.

Cheng, F. F. \& Wu, C. S. (2010). Debiasing the framing effect: The effect of warning and involvement. Decision Support Systems, 49(3): 328-334.

Coulter, K. S. \& Punj, G. (1999). Influence of viewing context on the determinants of attitude toward the ad and the brand. Journal of Business Research, 45, 47-58.

De Vries, H. \& Backbier, E. (1994). Self-efficacy as an important determinant of quitting among pregnant women who smoke: the $\phi$ - pattern. Preventive Medicine, 23, 167174.

Dickinson, S. \& Holmes, M. (2008). Understanding the emotional and coping responses of adolescent individuals exposed to threat appeals. International Journal of Advertising, 27(2): 251-278.

Dutta, M. J. \& Vanacker, B. (2000). Effects of personality on persuasive appeals in health communication. Advances in Consumer Research, 27, 119-124.

Elliott, B. J. (2005). The use of threat (fear) to reduce adolescent risk taking: A Literature review. Unpublished report prepared for VicRoads.

Fishbein, M. \& Ajzen, I. (1975). Belief, attitude, intention and behavior: an introduction to theory and research reading. MA: Addison-Wesley.

Godin, G. \& Kok, G. (1996). The theory of planned behavior: a review of its applications in health-related behaviours. American Journal of Health Promotion, 11, 87-98.

Hastings, G., Stead, M. \& Webb, J. (2004). Fear appeals in social marketing: Strategic and ethical reasons for concern. Psychology \& Marketing, 21, 961-986.

Holloway, A. \& Watson, H. E. (2002). Role of self-efficacy and behavior change. International Journal of Nursing Practice, 8(2): 106-115.

Hovland, C. I. \& Janis I. L. (1959). Personality and persuasibility. New Haven: Yale University Press.

Hsu, T. K. (2003). Consumer psychology. Taipei: Tunghua Book Store. 
Huang, S. J. (1998). Why they smoke? College students' essential material analysis sample. School Hygiene, 33, 315.

Laskey, H. A., Fox, R. J. \& Crask, M. R. (1995). The relationship between advertising message strategy and television commercial effectiveness. Journal of Advertising Research, 35(2): 31-39.

LaTour, M. S. \& Rotfeld, H. J. (1997). There are threats and (maybe) fear-caused arousal: theory and confusions of appeals to fear and fear arousal itself. Journal of Advertising, 26(3): 45-59.

Lin, C. H. (2005). Consumer behavior. Taipei, Taiwan: Zhisheng Press.

Lutz, R. J. (1985). Affective and cognitive antecedents of attitude toward the ad: a conceptual framework, in L. F. Alwitt and A. A. Mitchell (Eds.). Psychological process and advertising effects: theory, research, and application, hillsdale. (45-63) NJ: Lawrence Erlbaum Associates.

MacKenzie, S. B. \& Lutz, J. R. (1989). An empirical examination of the structural antecedents of attitude toward the ad in an advertising pretesting context. Journal of Marketing, 53(2): 48-65.

Maheswaran, D. \& Meyers-Levy, J. (1990). The influence of message framing and issue involvement. Journal of Marketing Research, 27(3): 361-367.

Meyerowitz, B. E. \& Chaiken, S. (1987). The effect of message framing on breast self-examination attitudes, intentions, and behavior. Journal of Personality and Social Psychology, 52(3): 500-510.

Moorman, M. \& van den Putte, B. (2008). The influence of message framing, intention to quit smoking, and nicotine dependence on the persuasiveness of smoking cessation messages. Addictive Behaviors, 33(10): 1267-75.

Oster, G., Colditz, G. A. \& Kelly, N. L. (1984). The economic costs of smoking and benefits of quitting for individual smokers. Preventive Medicine, 13, 377-389.

Reardon, J. \& Miller, C. (2008). Smoking prevention messages for adolescents: how intensity, valence, and recipient of consequences affect attitude toward the ad and intent to smoke. Journal of Marketing Theory \& Practice, 16(1): $67-77$.

Rosenstock, I. M., Strecher, V. J. \& Becher, M. H. (1988). Social learning theory and the health belief model. Health Education Quarterly, 15 (2): 175-183.

Rossiter, J. R. \& Thornton, J. (2004) Fear-pattern analysis supports the fear-drive model for antispeeding road-safety TV Ads. Psychology \& Marketing, 21(11): 945-960.

Rothman, A. J. \& Salovey, P. (1997). Shaping perceptions to motivate healthy behavior: Therole of message framing. Psychological Bulletin, 121(1): 3-19.

Rothman, A. J., Salovey, P., Turvey, C. \& Fishkin, S.A. (1993). Attributions of responsibility and persuasion: Increasing mammography utilization among women over 40 with internally oriented messages. Health Psychology, 12(1): $39-47$

Ruiter, R. A. C., Kok, G., Verplanken, B. \& Van Eersel, G. (2003). Strengthening the persuasive impact of fear appeal: The role of action framing. The Journal of Social Psychology, 143(3): 397-400.

Rutsohn, P. \& Sikula, A. (2007). Medical malpractice reform: a societal crisis or fear marketing? Journal of Medical Marketing, 7(2): 169-175.

Shimp, T. A. (1981). Attitude toward the ad as a mediator of consumer brand choice. Journal of Advertising, 10(2): 9-15.

Snyder, C. R. (1994). The psychology of hope: You can get to there from here. New York: Free Press.
Snyder, C. R. (2002). Hope theory: Rainbows in the mind. Psychological Inquiry, 13(4): 249-275.

Snyder, C. R., Harris, C., Anderson, J. R., Holleran, S. A., Irving, L. M. \& Sigmon, S. T. (1991). The will and the ways: Development and validation of an individual differences measure of hope. Journal of Personality and Social Psychology, 60, 570-585.

Tversky, A. \& Kahneman, D. (1981). The framing of decisions and the psychology of choice. Science, 211(4481): 453458.

Wilson, D. K., Wallston, K. A. \& King, J. E. (1990). Effects of contract framing, motivation to quit, and self-efficacy on smoking reduction. Journal of Applied Social Psychology, 20 (7): 531-547.

Wilson, J. Q. \& Kelling, G. L. (1982). Broken windows: The police and neighborhood safety. Atlantic Monthly, 249, 2938.

Witte, K. (1992). Putting the fear back into fear appeals: the extended parallel process model. Communication Monographs, 59, 329-349.

Wong, C. O. \& McMurray, N. E. (2002). Framing communication: communicating the antismoking message effectively to all smokers. Journal of Community Psychology, 30(4): 433-447.

Yang, D. J. \& Ma, T. K. (2011). Exploring anchoring and communication effects from message manipulation: an experimental study about recycling. Pan-Pacific Management Review, 14(2): 79-108.

Yi, Y. (1990). Cognitive and affective priming effects of the context for print advertisements. Journal of Advertising, 19(2): 40-48.

Zhang, J. X. \& Schwarzer, R. (1995). Measuring optimistic self-beliefs: A Chinese adaptation of the General SelfEfficacy Scale. Psychologia, 38(3): 174-181.

\section{ACKNOWLEDGMENT}

The author is thankful to the National Science Council of the R. O. C. for financial support (NSC 101-2410-H-214-009-SSS) and three anonymous reviewers who gave many writing suggestions. 


\begin{tabular}{|c|c|c|}
\hline Version & Advertisement content & Frequency \\
\hline $\mathbf{A}$ & $\begin{array}{l}\text { Smoking enables/ cessation can improve infertility, } \\
\text { abortion, flaccid paralysis and premature ejaculation. After } \\
\text { quitting, since the cigarette smell is eliminated, it will } \\
\text { shorten the distance between friends. }\end{array}$ & 19 \\
\hline B & $\begin{array}{l}\text { Smoking enables/cessation can improve related } \\
\text { periodontal diseases (such as periodontitis, gingival atrophy, } \\
\text { dental calculus and tooth abscission). After quitting, it's } \\
\text { easier to give others a more positive image. }\end{array}$ & 10 \\
\hline C & $\begin{array}{l}\text { Smoking enables/ cessation can improve related cancers } \\
\text { (such as lung cancer, nasopharynx cancer, oral cancer and } \\
\text { gastric cancer). After quitting, since the cigarette smell is } \\
\text { improved, boyfriends or girlfriends are keener on each } \\
\text { other. }\end{array}$ & 31 \\
\hline
\end{tabular}

Table 1. Pre-test advertisement content and frequency statistics 


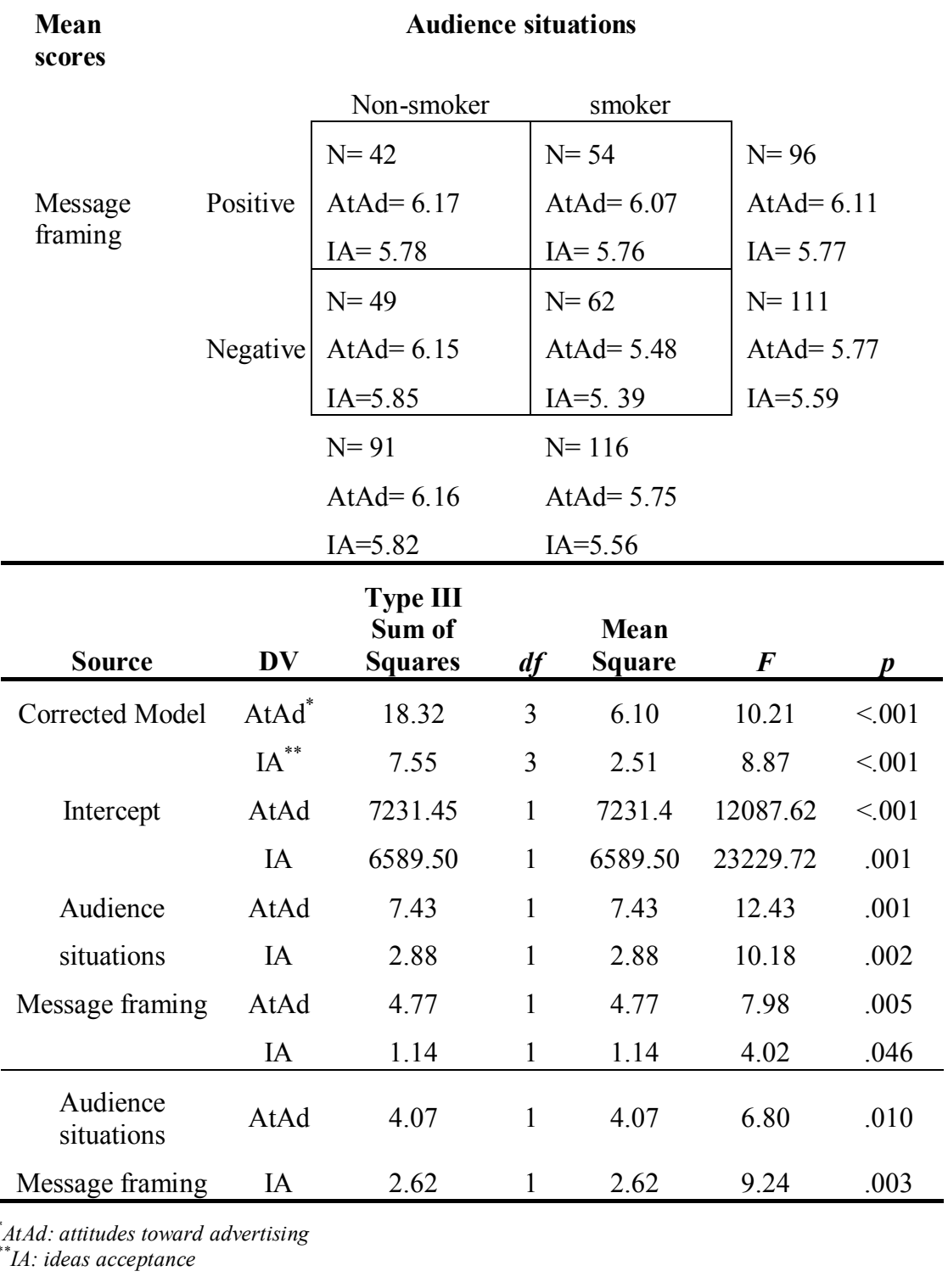

Table 3. Two-way ANOVA analysis of the communication effect of the message framing with Self-efficacy 
International Journal of Management, Economics and Social Sciences

Appendix-III

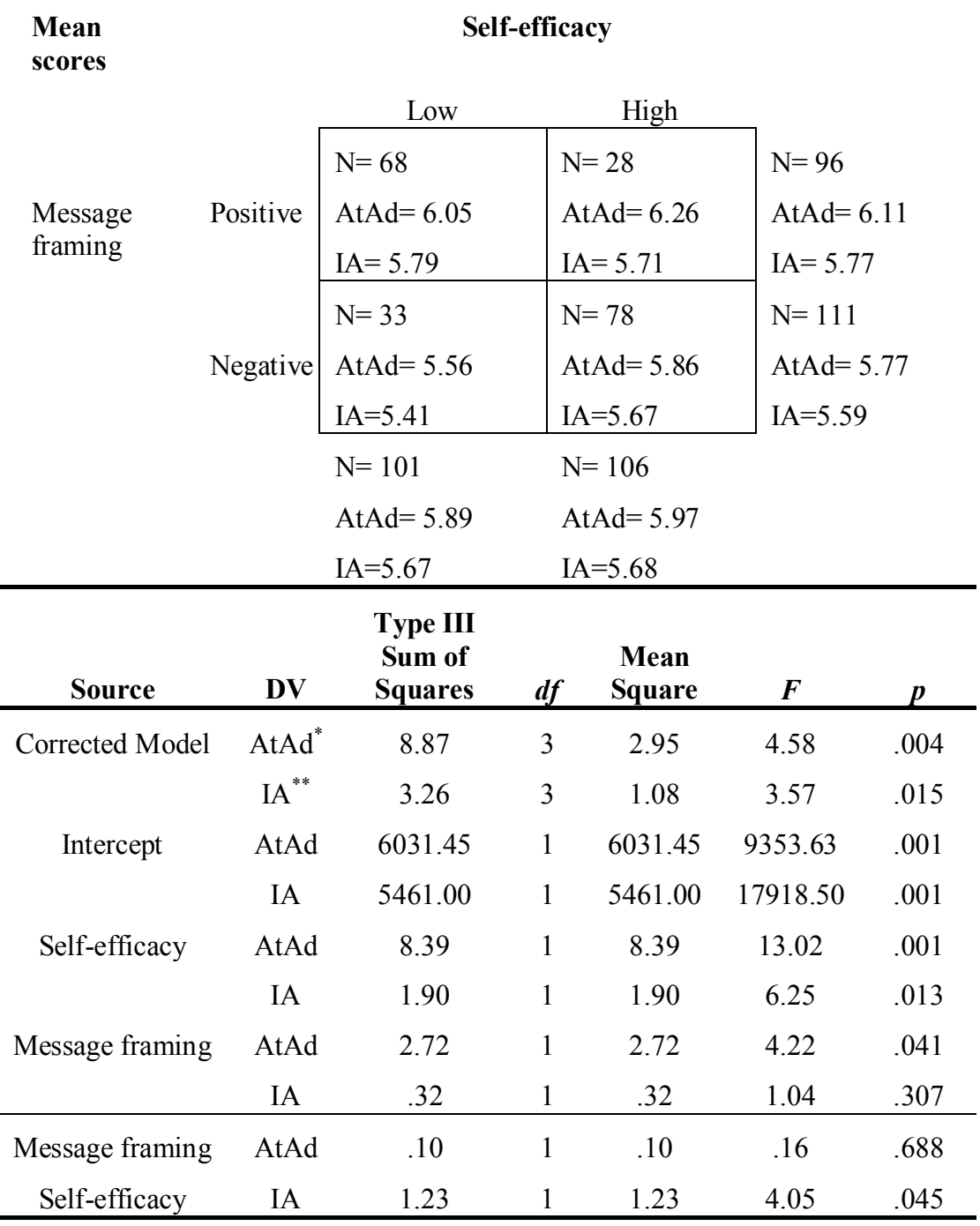

"AtAd: attitudes toward advertising

** IA: ideas acceptance

Table 4. Two-way ANOVA analysis of the communication effect of the message framing with Self-efficacy 